\title{
Materials for Respiratory Masks in the Context of COVID 19 Pandemic
}

\author{
NADINNE ROMAN ${ }^{1}$, DAN COJOCARU ${ }^{2}$, CLAUDIU COMAN ${ }^{3}$, ANGELA REPANOVICI ${ }^{2 *}$, \\ SANTIAGO FERRANDIZ BOU ${ }^{4}$, ROXANA STELIANA MICLAUS ${ }^{1}$ \\ ${ }^{1}$ Medicine Faculty, Transilvania University of Brasov, 29 Eroilor, 500036, Romania, \\ ${ }^{2}$ Product Design and Environment Department, Transilvania University of Brasov, 29 Eroilor Blvd., 500036, Romania, \\ ${ }^{3}$ Social and communication sciences Department, Transilvania University of Brasov, 29 Eroilor Blvd., 500036, Romania \\ ${ }^{4}$ The University of Valencia, Higher Polytechnic School of Alcoy, Universitat Politècnica de València, Department of \\ Mechanical and Materials Engineering, Plaza Ferrandiz-Carbonell, 03801 Alcoy [Alicante]-Spain
}

Abstract: In the context of the COVID-19 pandemic and the lack of protective equipment worldwide, we aimed to study the literature for finding guidelines in the 3D manufacture of respiratory masks. We have searched for papers in CI-EXPANDED, SSCI, A\&HCI, CPCI-S, CPCI-SSH, BKCI-S, BKCI-SSH, ESCI, CCR-EXPANDED, IC, using ' $3 D$ printing materials sterilization' and ' $3 D$ printing materials disinfection' keywords. From 80 results in databases, after refining, we selected six papers. We have also searched for manufacturers' information regarding $3 D$ printing materials sterilization or disinfection. We have found seven materials that are suitable for $3 D$ printing and sterilization, with regards to multiple utilizations. Analyzing the properties and recommendations for sterilization of elements obtained by $3 D$ printing, a thorough filaments structures/behavior research for most of the $3 D$ models for printing is needed regarding synthetic polymers suitable for $3 D$ printing; also, to establish the physical and chemical properties resulted after the reactions with sterilizing substances. In the context of the COVID-19 pandemic, the authors want to help and find guidelines in the 3D manufacture for producing respiratory masks.

Keywords: 3D printing, medical devices, 3D printing materials, sterilization, COVID-19

\section{Introduction}

Since January 21, 2020, the World Health Organization [WHO] started to make reports on the Novel Coronavirus [2019-nCoV], stating that at the end of the year 2019, WHO China Country Office reported the first cases of unknown etiology pneumonia [1].

WHO decided to declared COVID-19 infection pandemic on March 11, 2020, and described as" spreading from China worldwide and being confirmed 118,319 [80 955 in China] infections at that date" [2].

On March 23, 2020, the confirmed cases with "COVID infection reached 362,051 cases, with 15,496 deaths and 100,657 recovered patients" [3].

The spread of the pandemic has been rapid in Europe, especially in Italy, France, Spain, and worldwide. Medical systems are facing a significant health crisis in terms of disposable protective materials [1].

One of the significant problems in this pandemic is the rapid spread of the SARS-Cov2 virus, which requires the use of multiple protective materials: gloves, surgical or respiratory masks, goggles, face shields, gowns, disposable protective materials for covering the head, neck, and lower limbs, including the feet [4].

The health systems and the population needs regarding the use of respiratory protection masks are outnumbered. Even though China is the world's leading manufacturer of medical masks, the confirmed COVID infection cases have decreased, and professional activity has resumed [2].

\footnotetext{
*email: arepanovici@unitbv.ro
} 
Thus, the shortage of protective materials is accentuated and generates a global health crisis. Many manufacturers of products made with 3D printing have started to manufacture face shields and protective [respiratory] masks to support the medical systems. The materials used in 3D printing play an essential role because their properties make them suitable or not for various applications such as industry, mechanics, and, last but not least, medicine.

Prostheses, orthoses, implants, and last but not least, artificial organs have revolutionized medicine and come to the aid of thousands of people. Next, we will present the main materials used in 3D printing, their properties, and the possibility of sterilization.

One of the companies that manufacture respiratory masks uses nanomaterials that are expensive and inaccessible. To this end, we conducted a brief and quick review of the literature to determine which materials are suitable for 3D printing and allow repeated sterilization or disinfection while preserving the properties of medical protection.

\section{Material and method}

We queried the CI-EXPANDED, SSCI, A \& HCI, CPCI-S, CPCI-SSH, BKCI-S, BKCI-SSH, ESCI, CCR-EXPANDED, IC, and PubMed databases, using keywords such as: "3D printing materials sterilization" and "disinfection of 3D printing materials". The results obtained and the refining methods articles were selected.

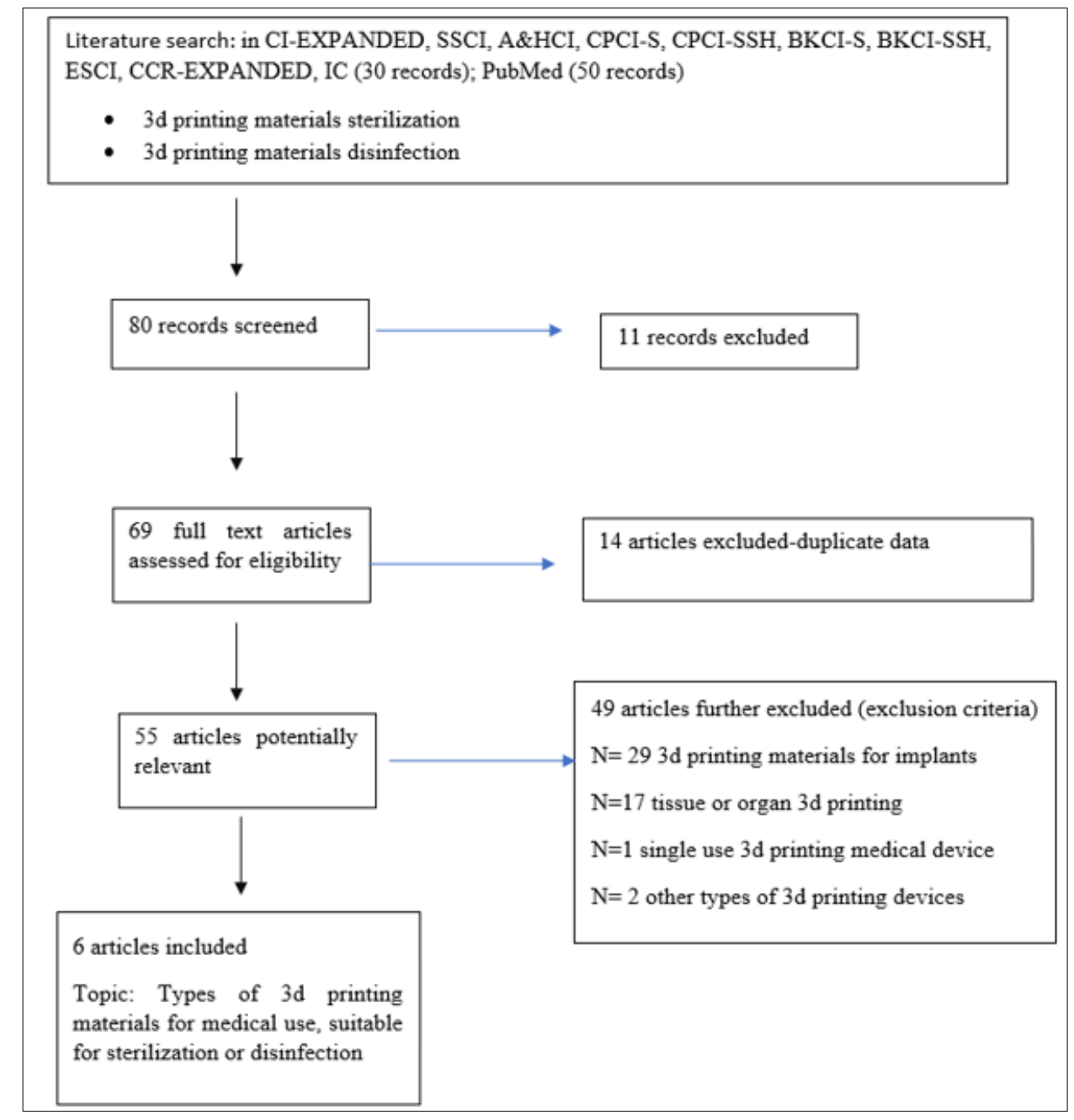

Figure 1. Scientific literature surve 


\section{Results and discussions}

In Table 1 are synthesized the selected articles with the main topic in the sterilization of 3D printed products.

Table 1. Selected articles (sterilization of 3D printed products)

\begin{tabular}{|c|c|c|c|c|c|c|c|}
\hline \multirow[t]{2}{*}{ No. } & \multirow[t]{2}{*}{ Title, Authors/Year } & \multicolumn{3}{|c|}{ Material } & \multirow[b]{2}{*}{ PCL $* * * *$} & \multirow[t]{2}{*}{ Sterilization by } & \multirow[t]{2}{*}{ Observation } \\
\hline & & PLA* & $\mathrm{ABS}^{* *}$ & $\begin{array}{l}\text { PET } \\
\text { G**** }\end{array}$ & & & \\
\hline 1. & $\begin{array}{l}\text { On the intrinsic sterility of } 3 D \\
\text { printing. Neches RY, Flynn KJ, } \\
\text { Zaman L, Tung E, Pudlo N/ } \\
\text { 2016. [5] }\end{array}$ & $\mathrm{X}$ & & & & $\begin{array}{c}\text { UV } \\
15 \text { watts } \\
\text { germicidal fluorescent bulb } \\
\text { [Philips, model G15T8] }\end{array}$ & $\begin{array}{l}\text { There is no mention of the } \\
\text { UV exposure time }\end{array}$ \\
\hline 2. & $\begin{array}{l}\text { Reproducibility, Accuracy, and } \\
\text { Effect of Autoclave Sterilization } \\
\text { on a Thermoplastic Three- } \\
\text { Dimensional Model Printed by } \\
\text { a Desktop Fused Deposition } \\
\text { Modelling Three-Dimensional } \\
\text { Printer. Boursier JF, Fournet A, } \\
\text { Bassanino J, Manassero M, } \\
\text { Bedu S, Leperlier D./2018 6] }\end{array}$ & $\mathrm{X}$ & & & & Autoclave sterilization & $\begin{array}{c}\text { It is one-time sterilization, } \\
\text { but it shows that PLA is } \\
\text { compatible with autoclave } \\
\text { sterilization }\end{array}$ \\
\hline 3. & $\begin{array}{c}\text { 3D printing surgical } \\
\text { instruments: Are we there yet?. } \\
\text { Rankin TM, Giovinco NA, } \\
\text { Cucher DJ, Watts G, Hurwitz } \\
\text { B, Armstrong DG. } 2014 \text { [7] }\end{array}$ & $\mathrm{X}$ & & & & $\begin{array}{l}\text { submersion in a glutaraldehyde } \\
\text { solution ( concentration } 2.4 \% \text {, } \\
\qquad p \mathrm{H}=7.5 \\
\text { parameters: } 20 \mathrm{~min}, 25^{\circ} \mathrm{C}\end{array}$ & $\begin{array}{l}\text { The authors state that are } \\
\text { necessary supplementary } \\
\text { fast protocols like "5 } \\
\text { minutes submersion at } \\
\text { 35C." }\end{array}$ \\
\hline 4. & $\begin{array}{c}\text { Additive Manufacturing of } \\
\text { Medical Instruments: A State- } \\
\text { of-the-Art Review. Culmone, } \\
\text { C. Smit, G. } 2019 \text { [8] }\end{array}$ & $\mathrm{X}$ & $\mathrm{X}$ & & & $\begin{array}{c}\text { Äutoclave at } 121 \text { or } 134^{\circ} \mathrm{C} \text { at } \\
60{ }^{\circ} \mathrm{C} \text { - PLA becomes soft } \\
\text { at } 88^{\circ} \mathrm{C} \text { - ABS deteriorates } \\
\text { Low-temperature sterilization } \\
\text { methods [below } 60{ }^{\circ} \mathrm{C} \text { ] use } \\
\text { Ethylene oxide gas (cycle of } \\
12-24 \mathrm{~h} \text { ) and hydrogen } \\
\text { peroxide gas plasma (cycle of } \\
28-75 \text { min) }\end{array}$ & $\begin{array}{l}\text { PA } 2200 * * * * \text { polymer } \\
\text { printed instruments will } \\
\text { be sterilized by autoclave } \\
\text { but only one time (not } \\
\text { sufficient for solving } \\
\text { blood contamination) }\end{array}$ \\
\hline 5. & $\begin{array}{c}\text { How to Sterilize } 3 D \text { Printed } \\
\text { Objects for Surgical Use? An } \\
\text { Evaluation of the Volumetric } \\
\text { Deformation of } 3 D \text {-Printed } \\
\text { Genioplasty Guide in PLA and } \\
\text { PETG after Sterilization by } \\
\text { Low-Temperature Hydrogen } \\
\text { Peroxide Gas Plasma. Olivier } \\
\text { Oth, César Dauchot, Maria } \\
\text { Orellana, Régine Glineur. } 2019 \\
\text { [9] }\end{array}$ & $\mathrm{X}$ & & $\mathrm{X}$ & & $\begin{array}{l}\text { hydrogen peroxide sterilizer, } \\
\text { 'low temperature }\left(55^{\circ} \mathrm{C}\right) \text {, one } \\
\text { short cycle of } 50 \mathrm{~min}\end{array}$ & $\begin{array}{l}\text { The best alternative in } \\
\text { order to avoid the } \\
\text { deformation of PLA and } \\
\text { PETG 3D-printed objects } \\
\text { (during autoclave) }\end{array}$ \\
\hline 6 & $\begin{array}{c}\text { Effects of different sterilization } \\
\text { processes on the properties of a } \\
\text { novel 3D-printed } \\
\text { polycaprolactone stent. } \\
\text { Antonio J. Guerra Paula Cano } \\
\text { Marc Rabionet Teresa Puig } \\
\text { Joaquim Ciurana. } 2018[10]\end{array}$ & & & & $\mathrm{X}$ & $\begin{array}{c}\text { Step 1- submersion in a } \\
\text { solution of } 70 \% \text { ethanol } \\
\text { overnight } \\
\text { Step } 2 \text {-washed two times with } \\
\text { phosphate-buffered saline } \\
\text { Step 3- exposed to UV light for } \\
30 \text { min } \\
\text { There was no alteration of the } \\
\text { properties }\end{array}$ & $\begin{array}{l}\text { Ethanol is very effective } \\
\text { for sterilization treatment } \\
\text { (barely affected the } \\
\text { material's properties) }\end{array}$ \\
\hline
\end{tabular}

*PLA-Polylactic Acid, **ABS- acrylonitrile butadiene styrene, $* * * P E T G$ - polyethene terephthalate glycol-modified, ****PCL-polycaprolactone, PA 2200-nylon powder 


\subsection{Polylactic acid [PLA] and polyethylene terephthalate glycol-modified [PETG]}

The polylactic acid [PLA] can be manufactured from non-toxic raw and renewable materials, the best reason to become one of the most promising biopolymers. PLA has come out as an important polymeric material with mechanical strength and process capacity, very suitable for biomedical use as per biocompatibility and biodegradability [11]. The properties of polylactic acid are found in Table 2.

Table 2. PLA and PETG properties [12, 13]

\begin{tabular}{|c|c|c|c|c|}
\hline \multirow[t]{2}{*}{ Properties } & \multicolumn{2}{|c|}{ Typical value } & \multicolumn{2}{|c|}{ Standard } \\
\hline & PLA & PETG & PLA & PETG \\
\hline Heat deflection temperature ( $0.45 \mathrm{MPa})$ & $55^{\circ} \mathrm{C}$ & $68^{\circ} \mathrm{C}$ & ISO 75 & ISO 75 \\
\hline Modulus of elasticity & $2.3 \mathrm{GPa}^{*}$ & $2.1 \mathrm{GPa}$ & ASTM D638 & ASTM D638 \\
\hline Maximum melting temperature & $145-160^{\circ} \mathrm{C}$ & $220-245^{\circ} \mathrm{C}$ & ISO 11357 & ISO 11357 \\
\hline Glass transition temperature & $55-60^{\circ} \mathrm{C}$ & $80-82^{\circ} \mathrm{C}$ & ISO 11357 & ASTM E1356 \\
\hline Elongation at flow & $2 \%$ & $14 \%$ & ASTM D638 & ASTM D638 \\
\hline Final traction force & 26.4 MPa** & $45.8 \mathrm{MPa}$ & ASTM D638 & ASTM D638 \\
\hline
\end{tabular}

PETG [Polyethylene Terephthalate Glycol-Modified], one of the most widely used filaments, is an ideal option for printing under mechanical stress. It is furthermore heat-resistant, more flexible, and less fragile than PLA. PETG is typically used in the printing of functional and mechanical parts. Since it has an excellent proper adhesion of the layer, it is also adequate for waterproof prints. However, it seems it is not suitable for tiny parts [14]. The properties of polyethylene terephthalate glycol-modified can be found in Table 2.

Hydrogen peroxide sterilization causes sub-millimeter morphological distortions and, because of that, is acceptable for surgical use. Avoiding 3D-printed objects' deformation makes hydrogen peroxide sterilization preferable to PLA and PETG during conventional autoclaves [steam sterilization] [9].

In the study of Savaris et al. [15], PLA films were sterilized with hydrogen peroxide plasma, saturated steam, and gamma radiation. Saturated steam sterilization determined the tremendous alteration, and the process impaired the chemical structure of PLA. Therefore, PLA showed marks of degradation and morphological, physical, and thermal alteration resulting from high pressure and temperature. Thus, the method is not suitable for PLA sterilization [15].

The sterilization using electron beam radiation, gamma radiation, and hydrogen peroxide plasma determined shifts in crystallinity, contact angle, and color, but these changes were not considerable, so these three processes can be safely used for PLA sterilization [15].

Ethylene oxide sterilization determines alterations in polymeric structures inflict molecular weight loss and engender a toxic deposit on the object's surface. Therefore, the PLA or PETG sterilization with ethylene oxide is not suitable [16].

Besides, dry heat sterilization is presently banned in the European Union hospitals since sterilization by radiation is used in the food and medical device industry. Still, it is considered not fitting for use in hospitals. It is recommended to avoid ethylene oxide, as it causes alterations in the polymeric structures. In opposition, sterilization at a low temperature with hydrogen peroxide produces no toxic residues remained on the sterilized pieces. This mechanism is prompt, reliable, and does not demand aeration time requested by ethylene oxide [17]. 


\subsection{Polypropylene $[\mathrm{PP}]$}

Polypropylene is a highly useful material in manufacturing medical devices and packaging materials as per its high transparency, good protective quality, and radiation resistance. Medical grade polypropylene manufacturers claim that both the polypropylene and its copolymers with ethylene can be a competitor to PVC [polyvinyl chloride colloquial], glass, and other plastics. Medical applicability for polypropylene includes blister packs, flexible bags, syringes, disposable hospital tubes, test tubes, glasses, and pipettes. The main advantages of polypropylene are firm, resistance, relatively inflexible, and with a small weight. The thermoplastic polymer [polypropylene] withheld most of its mechanical properties even at high temperatures and proved to have a very good performance related to cost. It has remarkable mechanical and breaking strength; it can be used at the autoclave and has excellent dielectric features. It becomes fragile at low temperatures [usually lower than $-32^{\circ} \mathrm{C}$ ] and has no resistance to weather or radiation without additives or impact modifiers. Table 3 compares the properties of three types of polypropylene materials, isotactic polypropylene, being the most frequently used in medical applications.

Table 3. Properties of Polypropylene [18,19]

\begin{tabular}{|c|c|c|c|c|}
\hline Property & Unit & A-pp* & $\mathbf{A - P P} * *$ & $\mathbf{i}-\mathbf{P P} * * *$ \\
\hline Density & $\mathrm{g} / \mathrm{cc}$ & 0.86 & 0.9 & 0.905 \\
\hline Opacity & $\%$ & 70 & 2 & 10 \\
\hline Melting point & ${ }^{\circ} \mathrm{C}$ & - & 168 & 163 \\
\hline Glass transition temperature & ${ }^{\circ} \mathrm{C}$ & -20 & -8 & -10 \\
\hline Heat deflection temperature (0.46 MPa or $66 \mathrm{psi})$ & ${ }^{\circ} \mathrm{C}$ & - & - & 100 \\
\hline Heat deflection temperature $1.8 \mathrm{MPa}$ or $264 \mathrm{psi}$ ) & ${ }^{\circ} \mathrm{C}$ & - & - & 55 \\
\hline Softening point & ${ }^{\circ} \mathrm{C}$ & $90-150$ & - & - \\
\hline Tensile resistant & $\mathrm{MPa}$ & 0.8 & 61 & $30-35$ \\
\hline Elongation & $\%$ & $>1.000$ & - & $100-300$ \\
\hline Bending modulus & $\mathrm{GPa}$ & - & $1.0-1.3$ & $1.5-2.0$ \\
\hline Impact resistance & $\mathrm{J} / \mathrm{m}$ & - & - & $50-120$ \\
\hline$\%$ Crystallinity & $\%$ & $5-10$ & $30-40$ & $40-60$ \\
\hline
\end{tabular}

\section{Polypropylene sterilization}

For isotactic polypropylene, the heat deflection temperature [HDT] is $100^{\circ} \mathrm{C}$ and can thus be steamsterilized or autoclaved. But the use of the autoclave is limited to several cycles. Novel grade materials with superior heat resistance can hold up autoclave sterilization temperatures.

Regarding steam sterilization, previous research did not report any alterations in crystallinity or physical properties. It can also be used to sterilize polypropylene and ethylene oxide since no significant modifications in properties were observed after one or three cycles.

The exposure of polypropylene to gamma radiation for sterilization is preceded by stabilization with free radical scavengers to prevent discoloration and alteration. Because polypropylene maintained its stability after radiation exposure and accelerated aging at $80^{\circ} \mathrm{C}$, the stabilized polypropylene supports after nine weeks of almost $80 \%$ of its quality, compared to a standard not stabilized polypropylene, which loses $80 \%$ of its properties after nine weeks.

\subsection{Nylon}

Nylon is a reliable, ductile, and versatile material, especially suitable for mechanical components. It is flexible in thin layers but with excellent adhesion between layers. Nylon should be stored in a dry environment. Otherwise, it quickly absorbs moisture from the air, and bubbles form in the material-the dry nylon filament prints smooth objects with a glossy finish. The advantages of using nylon are that it has good mechanical properties and is hard-to-deformed. It has chemical resistance, being stable, and flexible and robust material. The disadvantages of using nylon are related to the difficulty of printing and the need to keep it in a dry environment [20]. 
Nylon 680 is a high quality, very durable nylon made from a polymer approved by the US Food and Drug Administration [FDA]. It is designed to be used in various industries, such as medicine, dentistry, robotics, and food processing. In the 3D printing industry, the materials' compatibility with sterilization processes is a rare characteristic of the material; therefore, it is a unique property of Nylon 680. This engineering grade nylon has been specially designed for 3D printing; it can be printed at slightly lower temperatures than other nylon filaments and can withstand oxidation with ethylene and steam sterilization processes.

Parts printed with Nylon 680 were independently examined and have a higher strength than other available 3D printing materials, including PLA or ABS injection molded pieces. In the laboratory test, the printed 3D samples of nylon 680 achieved $197.42 \mathrm{MPa}$ [28,634 psi] tensile modulus tension, considered average; therefore, Nylon 680 has an opacity of about $20 \%$ and very low shrinkage capacity, remaining accurate in $3 \mathrm{D}$ printing.

As per very low shrinkage capacity, Nylon 680 makes it possible to print tight tolerances pieces. If functional parts require a specific size, Nylon 680 material should match the load. Thus, the Nylon 680 material maintains a slippery nylon surface, as required by medical and industrial use [21].

\section{Sterilization of Nylon 680}

Regarding the sterilization of Nylon 680 material, it is compatible with ethylene oxide sterilization at low temperatures and with sterilization using steam or boiling, meaning the sterilization methods that are used globally in scientific research laboratories.

Sterilization has a significant meaning for the researchers because it eliminates all fungi, bacteria, and other microbes that can interfere with experimental conditions. The material's compatibility with sterilization processes is a unique property of Nylon 680 material, and it is a rare material feature in the $3 \mathrm{D}$ printing industry. Thus, at the time of printing, Nylon 680 is processed at a temperature of 250$255^{\circ} \mathrm{C}$, with a melting point of $210^{\circ} \mathrm{C}$. As far as the nozzle is concerned, nozzles of any size can be used. It is an excellent material for printing high-strength and functional 3D devices, being more robust than PLA and ABS.

\subsection{Elastic material (Flex)}

By its nature, Flex [TPU] is quite similar to PLA plastic, being also a product of natural origin. TPU is a flexible filament, thermoplastic elastomer or polyurethane that allow a print to stretch or bend easily. The main production material is corn. This not only ensures ecological safety but also ensures complete biodegradability. Unlike various other plastics, the use of Flex is more rational and safer. Main properties: Maximum melting temperature: $200-210^{\circ} \mathrm{C}$, Softening point $-110^{\circ} \mathrm{C}$, Operating temperature $--100+100^{\circ} \mathrm{C}$, Glass transition temperature: $60-70^{\circ} \mathrm{C}$, Elongation at break $600 \%$, Bend strength -5.3 MPa $1.75 \mathrm{~mm}$, Tensile strength - 17.5 MPa $1.75 \mathrm{~mm}$, modulus of elasticity, tensile strength - $0.06 \mathrm{GPa}$, Flexible mode - 0.07 GPa. There are some popular brands, like NinjaT. ek Ninjaflex, Armadillo, Cheetah, Polymaker PolyFlex, eSun TPE, Sainsmart Flexible TPU.

\subsection{Polycarbonate / Resins [ASA/ABS]}

\subsubsection{ASA (Acrylonitrile styrene acrylate)}

ASA polymers have obvious similarities to ABS plastics (same amorphous and mechanical properties). ASA polymers are the impact of SAN polymers [Styrene-acrylonitrile resin] modified with an acrylic rubber, so the special abilities of this material are due to the acrylic ester elastomer [22]. ASA parts have good chemical resistance but also high heat resistance, good impact resistance even at low temperatures [23]. In the current life, the properties of ASA are much less affected by the weather. 
Table 4. Thermal properties of ASA [23]

\begin{tabular}{|c|c|}
\hline Conditions & Deflection temperature \\
\hline $0.45 \mathrm{MPa}-6.40 \mathrm{~mm}$ & $96.0^{\circ} \mathrm{C}$ \\
\hline $1.8 \mathrm{MPa}-6.40 \mathrm{~mm}$ & $86.0^{\circ} \mathrm{C}$ \\
\hline
\end{tabular}

Purified water or sterile water: $\max 100 \mathrm{CFU} / \mathrm{mL}$ is $0.5 \mathrm{EU} / \mathrm{mL}$ - residues from hard water or water with higher contamination (with microorganism and endotoxins) may cause staining of the instruments or effective decontamination cannot be achieved [24]. This method is used to remove organic residues by immersion in a decontamination bath with a cleaning agent.

The instruments can be washed with a cleaning agent in a washing machine and disinfectant; the temperature can be set according to the material being cleaned. Avoid cleaning agents with a high $p \mathrm{H}$ [> 8.5]. Dry it by using a compressed air device or clean wipes [25].

The aforementioned purified or sterile water can be used with a syringe in the case of instruments with hollow parts and grooves. The substance must reach all sides and the entire surface. A magnifying tool shall also be used in appropriate lighting conditions to verify the above procedures.

\section{Sterilization can be performed with Class B steam}

The devices are equipped with a vacuum pump to remove air from the room and to ensure the sterilization of porous materials, wrapped articles, or instruments with cavities [25].

Chemical sterilization with formaldehyde and ethylene oxide is not recommended. Also, exposure to high temperatures for a long time can reduce the life of instruments. The use of purified or deionized water is strongly recommended. After sterilization, the instruments must be stored in sterile containers or a rigid container [25].

\subsubsection{ABS}

ABS or acrylonitrile butadiene styrene is a thermoplastic polymer commonly used for injection moulding applications [26]. Products made of ABS material can be industrially sterilized with gamma radiation [27]. They can also be used for sterilization - plasma, oxidizing agents [hydrogen peroxide, chlorine dioxide or liquid sterilizers - glutaraldehyde]. Heat sterilization is also possible [steam, dry heat] [28].

\subsection{Chlorinated polyethene [CPE]}

Chlorinated polyethene $[\mathrm{CPE}]$ is a material obtained by substituting hydrogen atoms with chlorine atoms in high-density polyethene [HDPE]. CPE characteristics are related to the fact that the material is a saturated rubber with superior chemical attributes, it has a good flame-retardant property and is combustion resistant. Highly flammable materials can be manufactured at low cost by combining CPE with proportional ratios of flame-retardant antimony, chlorinated paraffin and $\mathrm{Al}[\mathrm{OH}]_{3}$.

It is proved that CPE is non-toxic and does not encompass heavy metals and PAHs [Polycyclic Aromatic Hydrocarbons], thus, this material is conforming into environmental demand, it has high filling capacity and can be used in conformity with various performance necessities. Thus, two classes of CPE are available: resin-type CPE and elastomer-type CPE.

CPE can be used as a standalone material or mixed with PVC, polyethene, polypropylene, polystyrene, ABS and even polyurethane. CPE can be available as a high-performance rubber. When allied with other rubber materials, it is commonly used in the production of wires and cables, such as standard use wire cable, UL and VDE, and in the production of hydraulic hoses, in the production of car hoses, plastic strips and sheets [29].

PET [polyethene terephthalate] is the most commonly used plastic in the world: it is found in plastic bottles, food containers, textile fibers. It is a translucent material with a superior chemical resistance, therefore being suitable for food industry use. The PET variant utilized in 3D printing is PETG. The G 
at the end represents modified Glycol and has meaning regarding a change in the chemical structure of the polymer that makes it more transparent, less fragile and easier to manufacture than ordinary PET.

\section{Sterilization of CPE}

The following different procedures were selected for the disinfection and sterilization of CPE and PET / PETG:

- Plasma sterilization is a promising alternative to sterilizing chemicals for a variety of applications, such as food packaging, water disinfection, and sterilization of medical instruments and implants.

- Vacuum UV radiation and plasma-produced UV radiation are the main sterilization mechanisms of bacilli and fungal spores sprayed on substrates [27].

- Formaldehyde sterilizers are designed to sterilize heat-sensitive, non-steam resistant items. The sterilizing agent is a formaldehyde solution [2\%] which ensures very safe conditions for both operating staffs, patients and the environment.

- Gamma radiation is electromagnetic, penetrating, nuclear radiation. Of interest for the treatment with ionizing radiation is the radiation obtained from sources with radioactive isotopes Cobalt-60 and to a lesser extent, Cesium-137 [30].

\subsection{High Impact Polystyrene [HIPS]}

HIPS [High Impact Polystyrene] is a modification of standard polystyrene by the addition of butadiene rubber. This material guarantees easy processing, good impact resistance and low costs, being the cheapest thermoformable material. Properties of HIPS are presented in Table 5.

Table 5. Thermo-physical properties HIPS [31]

\begin{tabular}{|c|c|}
\hline Melting temperature & $180-270{ }^{\circ} \mathrm{C}$ \\
\hline Density & $1.03-1.08 \mathrm{~g} / \mathrm{mL}$ \\
\hline Coefficient of thermal expansion $\times 10^{-5}$ & $8-10 \mathrm{~cm} /\left[\mathrm{cm} \cdot{ }^{\circ} \mathrm{C}\right]$ \\
\hline Heat deflection temperature of $0.5 \mathrm{MPa}$ & $87-93^{\circ} \mathrm{C}$ \\
\hline Heat deflection temperature, $1.8 \mathrm{MPa}$ & $75-91^{\circ} \mathrm{C}$ \\
\hline Thermal conductivity & $0.16-0.22 \mathrm{~W} / \mathrm{mK}$ \\
\hline
\end{tabular}

\section{7.a. Sterilization of HIPS}

\section{7.a.1 EtO/FORM - Ethylene Oxide / Formaldehyde}

Ethylene oxide gas is mainly used for sterilizing tools sensitive to temperatures above $60^{\circ} \mathrm{C}$, such as plastics or moisture-altering materials. Ethylene oxide treatment is performed between $30-60^{\circ} \mathrm{C}$ with a more than $30 \%$ humidity of and a gas concentration of $200-800 \mathrm{mg} / \mathrm{L}$. A complete cycle takes longer than steam sterilization, usually 16-18 h.

To carry out the ethylene oxide sterilization process, the materials must have the property of porosity. Because Ethylene oxide penetrates well through porous materials (medical grade paper and polyolefin fabrics), consequently is very effectively used in sterilizing systems with adequate porosity. Also, the duration of the sterilization cycle is relatively long. However, EtO gas is highly flammable, toxic and carcinogenic and because of that a long cycle requires aeration to remove toxic residues especially after sterilization. The bactericide mechanism of Formaldehyde is represented by coagulation process of cellular proteins. Ethylene oxide can be used as a gaseous fumigant, so formaldehyde sterilization is complex and less effective than other sterilization methods. In general, this process is used only if no other sterilization methods are available or are considered unsuitable for sterilizing the article [32].

Studies show that HIPS materials are compatible with ethylene oxide sterilization. However, overexposing them to such sterilization treatments should be avoided due to the existence of the stearic component in the polymer matrix. Five consecutive cycles of ethylene oxide sterilization will weaken the material. This is observed by decreasing the index of elongation at break. After repeated cycles of sterilization with ethylene oxides, the fragility significantly decreases, so that the index of elongation at 
break after six months, respectively one year is much lower than it was two weeks after sterilization. [33]

\section{7.a.2 Hydrogen peroxide (oxygenated water)}

Hydrogen peroxide is used to sterilize objects and materials that are sensitive to high temperature and heat. It is a strong oxidant, and through it can destroy a wide spectrum of pathogens, in a wide concentrations' interval (35-90\%), reasons to be useful in medical sterilization, beside the short duration of a sterilization cycle (considered a major advantage). Compared to the sterilization cycle time for ethylene oxide [discussed above], which can be up to $18 \mathrm{~h}$, some modern hydrogen peroxide sterilizers have a cycle of up to $28 \mathrm{~min}$. However, the penetration capacity of hydrogen peroxide is not as good as ethylene oxide and therefore there are limitations for an efficient sterilization. Its vapors are also dangerous, targeting the eyes and respiratory system [30]. No information was found on how hydrogen peroxide affects HIPS materials.

\section{7.a.3 Gamma radiation}

The best method of sterilization is Gamma rays, as per a very good penetrating capacity, being used as ideal method to sterilize disposable medical equipment (syringes, cannulas, needles and other devices, especially those cannot be sterilized with other methods). The radioactive Co 60 isotope can disintegrate to produce gamma rays, which can penetrate deeper into materials than beta rays before losing collision energy. Not least, Gamma radiation requires bulky shielding to protect the operators and the storage of radioactive isotope Cobalt-60 (continuously emit gamma rays) requires storage facilities. The duration of product exposure to radiation is 10 to $20 \mathrm{~h}$, depending on the power of the source [30]. According to studies, the physical properties of HIPS materials are not altered for exposure to doses up to 100 kilogray. Discoloration of the material occurs immediately after the sterilization process, but this effect is temporary if the dosage value is from 25 to 100 kilogray. Above this value, the discoloration is permanent. There was also a slight increase in tensile strength with increasing doses of gamma radiation [33].

In conclusion, the new COVID-19 virus is a current global problem. It continuously causes disastrous effects on humanity in the economic, social and political fields. At the same time, it puts more pressure on the medical system and on public health policies, amplifying the risks to which the medical staff in healthcare is exposed [34]. Doctors trained in combating this virus are also facing, besides not knowing its behavior, the lack of protective elements and elements necessary for the equipment to support and maintain human life in critical situations.

As a result, 3D printers have become an effective solution to help partially solve existing problems, namely printing these missing elements by 3D modelling. This technology has served to partially solve by printing the necessary protective elements for medical employees, who most often face this lack. Elements necessary for protective masks, visors, valves have been manufactured by 3D printing. Even if the design and production of these objects were easily achievable, later the problem of reusing printed elements that came in contact with high-risk or contaminated infection environment was identified.

At the same time, as there is a need to reuse some printed parts, classical sterilization methods already known on other occasions in medicine were used, such as processing with saturated steam, hydrogen peroxide, ethylene oxide, electron beam radiation and gamma radiation and others. From the previous experience of the manufacturers of these parts for the use of medical staff, it has been proven that these methods are very effective for some types of material used in printing and others having harmful effects for others.

Based on this practical experience, it is necessary to research in detail the structure/behavior of the filaments most often used to print 3D models: PLA, ABS, PETG, etc.], to establish the physical and chemical properties after reactions with sterilizers. Attracting the participation in research director of the economic environment [companies] that produce the raw material [filament], and medical institutions, to obtain some recommendations on the more efficient design, use and maintenance of printed products. 
Their recommendations and research can help develop protocols [requirements] and standards in the production and implementation of printed 3D models for medical purposes. In this way, both companies and volunteers who own 3D printers with technical specifications that meet the standards can contribute to the design and production of the necessary parts, both individually and in collaboration.

\section{Conclusions}

Since the development of 3D printing, over the past decades, the domain of application has evolved significantly [35]! From the experience of making parts required during this period, both advantages and disadvantages of using 3D printers were identified.

Advantages are: rapid mobility of production of the minimum required parts for protection models at the expense of a large number of local volunteers, flexibility to design new 3D models and print them, minimizing environmental pollution, involving large production systems, the existence of databases on the Internet with different possible models to be printed without design intervention.

Disadvantages identified are lack of minimum printing standards corresponding to certain quality levels, lack of quality control of printed products from a company accredited in the field, the multitude of types of 3D printers with their SOFTWARE components that impose certain model-specific processes when printing 3D parts, use of different raw materials [PLA, ABS, PETG, etc.] and its manufacturer on the quality of printed parts, the lack of structures dealing with the collection and the reuse of these products and respectively the short-term environmental pollution with printed parts for this purpose, the risk of the inefficiency of the disinfection methods of the 3D models used.

There are some developing research directions to take in consideration to solve the limits of this research:

Q1: The mask must be able to filer the coronavirus, and the printed parts generally have tiny holes which will let the virus go through. How to sterilize these products? Q2: Some kind of materials can be used for sterilization. The PETG or ABS produces can have sterilization effects?

Following the analysis of the above-mentioned advantages and disadvantages, we find that there is a need for thorough research into the possibility of repeated sterilization of 3D printed objects and most efficient methods to carry it out.

\section{References}

1.***OMS. Situation Report-18 SITUATION IN NUMBERS total and new cases in the last 24 hours. Coronavirus Dis 2019 [Internet]. 2020 [cited 2020 May 25];2019[February]:7. Available from: https://www.who.int/docs/default-source/coronaviruse/situation-reports/20200207-sitrep-18-

ncov.pdf?sfvrsn=fa644293_2

2.WANG W, TANG J, WEI F. Updated understanding of the outbreak of 2019 novel coronavirus [2019nCoV] in Wuhan, China. J Med Virol. 2020 April 1;92[4]:441-7.

3.***Worldometer. Coronavirus Cases [Internet]. Worldometer. 2020 [cited 2020 May 25]. p. 1-22. Available from: https://www.worldometers.info/coronavirus/coronavirus-cases/\#daily-cases

4.TÖRÖK G, GOMBOCZ P, BOGNÁR E, NAGY P, DINYA E, KISPÉLYI B, et al. Effects of disinfection and sterilization on the dimensional changes and mechanical properties of $3 \mathrm{D}$ printed surgical guides for implant therapy - Pilot study. BMC Oral Health. 2020;20[1]:1-12.

5.NECHES RY, FLYNN KJ, ZAMAN L, TUNG E, PUDLO N. On the intrinsic sterility of 3D printing. PeerJ. 2016;2016[12]:1-20.

6.***Text F. Bone Research; Data on Bone Research Reported by J . F . Boursier and Co-Researchers [Reproducibility, Accuracy and Effect of Autoclave Sterilization on a Thermoplastic Three-Dimensional Model Printed by a Desktop Fused Deposition Modelling Three-Dimen. 2018;2018-20.

7.Hurwitz B, Armstrong DG. 3D printing surgical instruments: Are we there yet? J Surg Res. 2015;189[2]:193-7. 
8.CULMONE C, SMIT G, BREEDVELD P. Additive manufacturing of medical instruments: A stateof-the-art review. Addit Manuf [Internet]. 2019;27[October 2018]:461-73.

Available from: https://doi.org/10.1016/j.addma.2019.03.015

9.OTH O, DAUCHOT C, ORELLANA M, GLINEUR R. How to Sterilize 3D Printed Objects for Surgical Use? An Evaluation of the Volumetric Deformation of 3D-Printed Genioplasty Guide in PLA and PETG after Sterilization by Low-Temperature Hydrogen Peroxide Gas Plasma. Open Dent J. 2019;13[1]:410-7.

10.SHAHEEN E, ALHELWANI A, VAN DE CASTEELE E, POLITIS C, JACOBS R. Evaluation of Dimensional Changes of 3D Printed Models After Sterilization: A Pilot Study. Open Dent J. 2018;12[1]:72-9.

11.SINGHVI MS, ZINJARDE SS, GOKHALE D V. Polylactic acid: synthesis and biomedical applications. J Appl Microbiol. 2019;127[6]:1612-26.

12.ARAICA, L.S.A., RUÍZ AAB. Evaluación del comportamiento agronómico de ocho variedades de Malanga (Colocasia Esculenta) en las condiciones edafoclimáticas, Finca Buena Vista, comunidad El Tepeyac; 67. Available online: http://repositorio.unan.edu.ni/2986/1/5624.pdf (accessed on 23 May 2020)

13.***Prusa Research. Prusament PETG by Prusa Polymers. 2020;6:9-10.

14.***Acid P, Pra PP. Prusament PLA by Prusa Polymers IDENTIFICATION : RECOMMENDED PRINT SETTINGS : TYPICAL MATERIAL PROPERTIES : 2018;2-3.

15.SAVARIS M, BRAGA GL, DOS SANTOS V, CARVALHO GA, FALAVIGNA A, MACHADO DC, et al. Biocompatibility Assessment of Poly[lactic acid] Films after Sterilization with Ethylene Oxide in Histological Study in Vivo with Wistar Rats and Cellular Adhesion of Fibroblasts in Vitro. Int J Polym Sci. 2017;2017.

16.MODJARRAD K, EBNESAJJAD S. Handbook of Polymer Applications in Medicine and Medical Devices [Internet]. Handbook of Polymer Applications in Medicine and Medical Devices. 2013 [cited 2020 May 25]. 1-354 p. Available from: https://ebookcentral-proquest-com.pva.uib.no/lib/bergenebooks/reader.action?docID=1578348

17.KYI MS, HOLTON J, RIDGWAY GL. Assessment of the efficacy of a low-temperature hydrogen peroxide gas plasma sterilization system. J Hosp Infect. 1995;31[4]:275-84.

18.SASTRI VR. Plastics in Medical Devices: Properties, Requirements, and Applications: Second Edition. Plastics in Medical Devices: Properties, Requirements, and Applications: Second Edition. Elsevier/William Andrew; 2013. 1-305 p.

19.SASTRI VR. Plastics in Medical Devices [Internet]. Plastics in Medical Devices. 2010 [cited 2020 May 25]. Available from: https://www.elsevier.com/books/plastics-in-medical-devices/sastri/978-08155-2027-6

20.***Nylon 680 Spec [Internet]. [cited 2020 May 25]. Available from: https://taulman3d.com/nylon680-spec.html

21.***Nylon 680, 1Lb $3.00 \mathrm{~mm}$ [Taulman] [Internet]. [cited 2020 May 25].

Available from: https://www.blackmagic3d.com/product-p/n-680.htm

22.SCHEIRS J, PRIDDY D. Modern styrenic polymers: polystyrenes and styrenic copolymers. J. Wiley; 2003. 757 p.

23.***Asa T. ASA Filament. 31.

24.***Asa Dental. Make People Smile :: Manufacturer of dental instruments \& disposable material ASA DENTAL [Internet]. [cited 2020 May 25]. Available from: http://www.asadental.com/ 25.***asa Dental | REPROCESSING GUIDELINES [Internet]. [cited 2020 May 25]. Available from: www.asadental.com

26.***Technologies PE. What is ABS Material? - Plastic Extrusion Tech [Internet]. 2020 [cited 2020 May 25]. Available from: https://www.plasticextrusiontech.net/resources/what-is-abs-material/ 27.ALGHADI AM, TIRKES S, TAYFUN U. Mechanical, thermo-mechanical and morphological characterization of ABS based composites loaded with perlite mineral. Mater Res Express. 2020;7[1]. 
28.***Plastics Sterilization Resistance to Chemical, Steam or Gamma [Internet]. [cited 2020 May 25]. Available from:

https://omnexus.specialchem.com/polymer-properties/properties/sterilization-resistance-repeated 29.***Chlorinated Polyethylene [CPE] Characteristics and Application | VIA [Internet]. [cited 2020 May 25]. Available from: http://viachemical.com/chlorinated-polyethylene-cpe-characteristics-andapplication/

30.***Medical T, Regulation D, Mdr T, Mdr T, Products M, Regulation MD, et al. MDR requirements for labelling of Sterile Medical Products : 'Sterile Barrier System Indication' and 'Check the IFU' Results from the survey on proposals for new symbols. 2018;1-8.

31.***High Impact Polystyrene (HIPS)- Thermo-Physical Properties [Internet] [cited 2020 October 20]. Available from: https://polymerdatabase.com/Commercial\%20Polymers/PS2.html

32.***Sterility T, Levels A. GUIDANCE DOCUMENT Compatibility of materials used for Sterile Barrier Systems with sterilisation processes. [28322]:1-6. Available from: www.sterilebarrier.org,

33.OSSWALD TA, BAUR E, BRINKMANN S, OBERBACH K, SCHMACHTENBERG E. International Plastics Handbook. International Plastics Handbook. Carl Hanser Verlag GmbH \&amp; Co. KG; 2006. 34.Drugus D, Repanovici A, Popa D, Tirziman E, Roman N, Rogozea L, Miclaus R. Social impact of public health care in risk management implementation. Revista de Cercetare si Interventie Sociala.2017, 56:79-87

35.MICLAUS R, REPANOVICI A, ROMAN N. Biomaterials: Polylactic Acid and 3D Printing Processes for Orthosis and Prosthesis. 2017, Mater. Plast., 54 (1), 2017, 98

$\overline{\text { Manuscript received: } 6.08 .2020}$ 